\title{
Rancang Bangun Alat Pemanggang Dange
}

\section{Design of Dange Grill}

A. Fadly Nur Ikhwan Dahlan, Program Studi Pendidikan Teknologi Pertanian Fakultas Teknik Universitas Negeri Makassar, email: fadlynurikhwan45@gmail.com Andi Sukainah, Program Studi Pendidikan Teknologi Pertanian Fakultas Teknik Universitas Negeri Makassar, email: mamal_ptm@yahoo.co.id Jamaluddin P, Program Studi Pendidikan Teknologi Pertanian Fakultas Teknik Universitas Negeri Makassar, email: andisukainah@yahoo.com

\begin{abstract}
This research was carried out to improve the quality of dange to be more uniform in shape, hygienic, and reduce the cost required in the roasting process. The objectives of this research are to find out the design mechanism by using electricity. Research methods include planning, product design drawings, tools and materials used, design procedures, trials, and data analysis techniques. The working principle of this dange grill is this tool designed using nickel wire to convert electrical energy into heat energy. The first step is the manufacture the frame part which functions as a cantilever for the heating element and attached to the other components, then assembling an electrical installation that aims to connect electricity from the power source to the heating element. Mold pan and dange container are then installed on of the stand. The final stage is the process of installing tool walls and painting then tested. Result toasting dange uses a furnace with an average time of 14 minutes 33 seconds while the test results using the dange grill with time average of 13 minutes 20 seconds. In terms of cost efficiency, electric roasting equipment costs Rp. 20,135 in a single operation while the cost of traditional means costs $R p$ 20,397.
\end{abstract}

Keywords: Dange grill, design, dange.

\begin{abstract}
Abstrak
Penelitian ini dilakukan sebagai bentuk upaya untuk meningkatkan mutu dange agar lebih seragam dan higenis, serta mengurangi biaya yang diperlukan pada proses pemanggangan. Penelitian ini bertujuan untuk mengetahui mekanisme rancang bangun dengan menggunakan listrik. Metode penelitian meliputi desain perancangan, gambar desain produk, alat dan bahan yang digunakan, prosedur perancangan, uji coba, dan teknik analisis data. Prinsip kerja alat pemanggang dange adalah alat ini dirancang dengan menggunakan kawat nikelin untuk mengubah energi listrik menjadi energi panas. Tahap pertama dilakukan pembuatan bagian rangka yang berfungsi sebagai penopang dudukan elemen pemanas dan pada komponen lain. Kemudian, perakitan instalasi listrik yang bertujuan untuk menghubungkan listrik dari sumber listrik ke elemen pemanas. Panci cetakan dan wadah penampung dange kemudian di pasang pada dudukan. Tahap akhir yaitu proses pemasangan dinding alat dan pengecatan, kemudian dilakukan pengujian. Hasil penelitian pemanggangan dange menggunakan tungku dengan waktu rata-rata yaitu 14 menit 33 detik sedangkan hasil pengujian menggunakan alat pemanggang dange dengan waktu rata-rata yaitu 13 menit 20
\end{abstract}


detik. Dari segi efisiensi biaya alat pemanggang dange listrik membutuhkan biaya Rp 20.135 dalam sekali operasi sedangkan biaya dengan cara tradisional membutuhkan biaya Rp 20.397.

Kata Kunci: Alat pemanggang dange, rancang bangun, dange.

\section{Latar Belakang}

Teknologi membuat segala sesuatu yang dilakukan menjadi lebih mudah. Manusia selalu berusaha untuk menciptakan sesuatu yang dapat mempermudah aktivitasnya, hal inilah yang mendorong perkembangan teknologi yang telah banyak menghasilkan alat sebagai piranti untuk mempermudah kegiatan manusia bahkan menggantikan peran manusia dalam suatu fungsi tertentu. Pemilihan teknologi harus didasarkan juga pada aspek ekonomi dan efisiensinya sehingga jenis teknologi energi yang dipilih adalah yang paling optimal ditinjau dari segi aspek ekonomi dan lingkungan (Asrianto dkk., 2018).

Perkembangan teknologi kendali di bidang industri pada saat ini berkembang sangat pesat. Namun perkembangan tersebut belum terlihat di bidang industri yang memanfaatkan energi konvensional. Sebagai contoh adalah pada alat pemanggang. Alat pemanggang adalah suatu alat yang berguna untuk memasak dengan cara memanfaatkan energi panas untuk memasak, baik dengan menggunakan bara api, uap, maupun tegangan listrik.

Menurut Arhamsyah dkk. (2017), elemen pemanas listrik banyak dipakai dalam kehidupan sehari-hari, baik di dalam rumah tangga ataupun peralatan dan mesin industri. Bentuk dan tipe dari elemen pemanas listrik ini bermacam-macam disesuaikan dengan fungsi, tempat pemasangan, dan media yang akan dipanaskan. Panas yang dihasilkan oleh elemen pemanas listrik ini bersumber dari kawat ataupun pita bertahanan listrik tinggi (resistance wire). Biasanya bahan yang digunakan adalah nikelin yang dialiri arus listrik pada kedua ujungnya dan dilapisi oleh isolator listrik yang mampu meneruskan panas dengan baik hingga aman jika digunakan. Sebagian orang menggunakan alat pemanggang dengan bara api masih melakukannya dengan cara manual untuk membaliknya maupun dalam menambah bara apinya, sehingga hal ini dapat menimbulkan resiko apabila seseorang tersebut tidak hati-hati dalam melakukannya. Sebenarnya, hal ini dapat dilakukan secara praktis bila ada sebuah alat elektronik dan mekanis otomatis yang dapat membalik dan mengangkat panggangan serta dapat mengetahui seberapa banyak bara api yang diperlukan dengan kendali jarak jauh. Dengan adanya alat ini diharapkan masyarakat dapat lebih praktis dan dapat terhindar dari resiko alat pemanggang dengan bara api tersebut (Suciati, 2014). Alat pemanggang ini dapat digunakan pada pengrajin tradisional dange.

Dange adalah salah satu produk pertanian yang merupakan makanan tradisional dari Kabupaten Pangkep khususnya Kecamatan Segeri. Produk pertanian pada umumnya dihasilkan sebagai bahan mentah yang mempunyai sifat mudah rusak dan tidak tahan lama, sehingga memerlukan adanya suatu proses pengolahan agar dapat meningkatkan nilai tambah melalui produk olahan dalam bentuk setengah jadi maupun barang jadi.

Semua bahan pembuatan dange terbuat dari bahan yang alami dan sehat tanpa bahan pengawet ataupun zat pewarna 
yang dapat mengganggu kesehatan tubuh manusia. Selain rasanya yang enak, dange juga termasuk makanan yang sehat bagi para penderita diabetes militus. Kadar gula yang terdapat pada dange cukup rendah sehingga aman dikonsumsi dalam jumlah yang wajar. Dange juga bisa menjadi makanan ringan dan sebagai buah tangan.

Proses pemanggangan dange dilakukan secara manual dengan bara api arang kayu dan perlu menggunakan rice cooker sebagai alat memanaskan dange itu kembali. Hal tersebut memerlukan waktu yang lama, hasil yang tidak seragam dan mudah terkontaminasi oleh kotoran, baik berupa debu, polusi dan kotoran lainya dalam rangka memenuhi efektivitas dan efisiensi dalam proses pemanggangan dange. Oleh sebab itu, usaha perbaikan proses pemanggangan dange perlu diteliti dalam rangka meningkatkan efektivitas dan efiesiensi dalam proses pemanggangan agar dange menjadi lebih higenis dan seragam.

Upaya untuk meningkatkan mutu dange agar lebih seragam dan higenis, serta mengurangi biaya yang diperlukan pada proses pemanggangan, maka perlu dilakukan penelitian pada proses pengolahan dange, terutama pada proses pemanggangan yang dirancang secara sederhana, efektif, efisien, dan mempunyai kapasitas kerja yang tinggi, sehingga diharapkan dapat digunakan oleh para pengrajin dange. Alat pemanggang dange ini juga dapat berfungsi untuk menjaga suhu dange, sehingga para pengrajin tidak lagi harus menggunakan rice cooker sebagai alat untuk menjaga suhu dange.

\section{Bahan dan Metode}

Metode yang digunakan pada penelitian ini adalah penelitian rekayasa atau rancang bangun. Pada penelitian ini dilakukan pengujian kinerja alat pemanggang dange.

\section{Waktu}

Penelitian ini dilakukan selama 4 bulan dengan persiapan penelitian meliputi persiapan komponen dan peralatan penunjang, serta persiapan penelitian lanjutan meliputi penyiapan bahan untuk keperluan pembuatan peralatan dan pengambilan data.

\section{Tempat}

Penelitian ini dilaksanakan di Jl. Sultan Hasanuddin, Kabupaten Gowa, dan Laboratorium Program Studi Pendidikan Teknologi Pertanian Fakultas Teknik Universitas Negeri Makassar.

\section{Alat dan Bahan}

Alat dalam penelitian ini adalah (1) aplikasi Sketchup pro 2016, (2) mesin bor, (3) obeng kembang, (4) gergaji besi, (5) solder, (6) tang kombinasi, (7) gerinda tangan, (8) pahat, dan (9) multimeter.

Sedangkan bahan yang digunakan adalah (1) kawat nikelin, (2) baja ringan, (3) tripleks, (4) besi teflon, (5) adonan dange, (6) termofuse, (7) saklar dimmer, (8) baut dan mur, (9) termometer digital, (10) besi plat, (11) lem kapal, dan (12) dempul kayu.

\section{Prosedur Rancang Bangun}

Rancangan fungsional, struktural, dan prosedur perancangan pada penelitian ini diuraikan sebagai berikut:

1. Rangka (Gambar 1), berfungsi sebagai dudukan dari suatu alat. Agar rangka aman untuk digunakan maka harus dilakukan suatu perhitungan terhadap beban yang akan dikenakan ke rangka 
(Amirul dkk., 2017). Rangka dibuat dengan bentuk persegi panjang dengan menggunakan baja ringan dengan ukuran $20 \mathrm{~mm}$ x $40 \mathrm{~mm}$. Rangka dibuat dengan ukuran $480 \mathrm{~mm}$ x $480 \mathrm{~mm}$ dengan tinggi $840 \mathrm{~mm}$.

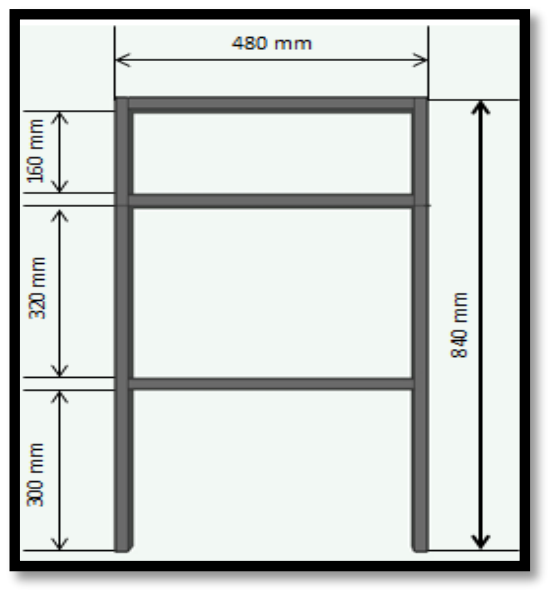

Gambar 1. Desain rangka tampak depan

Perakitan instalasi listrik pada alat pemanggang dange ini (Gambar 2) dirangkai menggunakan saklar dimmer yang kemudian dihubungkan dengan kabel anti panas. Kemudian dihubungkan ke termostate yang berfungsi sebagai pemutus aliran listrik jika suhu melewati ambang batas, dan kemudian secara otomatis memulai kembali proses memanaskan ketika suhu kembali berada dibawah ambang batas, kemudian mengalirkan energi panas ke kawat nikelin yang berfungsi sebagai elemen pemanas. Kawat nikelin yang digunakan adalah kawat nikelin $0,6 \mathrm{~mm}$ round wire $22 \mathrm{~m}$ yang dibentuk menyerupai pegas untuk menghantarkan panas ke panci panggangan secara merata. Mekanisme pindah panas pada alat ini adalah terjadi perpindahan panas secara radiasi dari kawat nikelin menuju panci panggangan. Perpindahan panas radiasi adalah proses perpindahan energi berupa panas yang terjadi melalui pancaran gelombang cahaya dari suatu zat ke zat yang lain tanpa zat perantara. Besar kecilnya radiasi suatu benda tergantung pada suhu benda dan jaraknya. Semakin tinggi suhunya maka semakin besar radiasi yang dikeluarkan, dan semakin jauh jaraknya, maka semakin kecil pancaran panasnya (Johan, 2016).

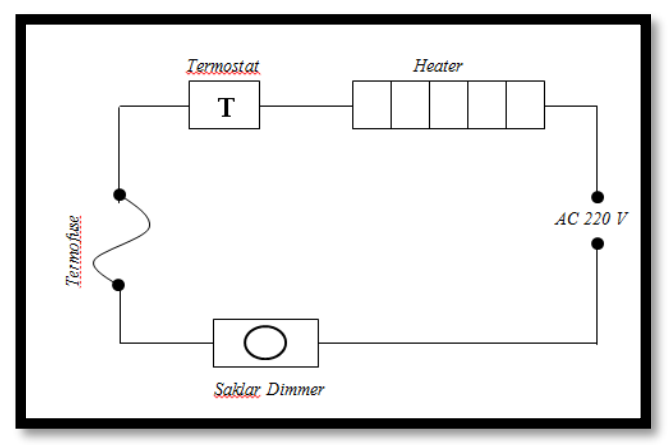

Gambar 2. Rangkaian listrik

2. Panci cetakan (Gambar 3) berfungsi sebagai wadah dalam memanggang dange sekaligus sebagai cetakan dange yang memiliki 20 buah lubang. Panci cetakan berukuran $320 \mathrm{~mm}$ x $170 \mathrm{~mm}$ dengan kedalaman masing-masing lubang adalah $40 \mathrm{~mm}$, ukuran sekat bagian dalam cetakan berukuran $2 \mathrm{~mm}$, dan ketebalan sekat bagian luar adalah 5 $\mathrm{mm}$.

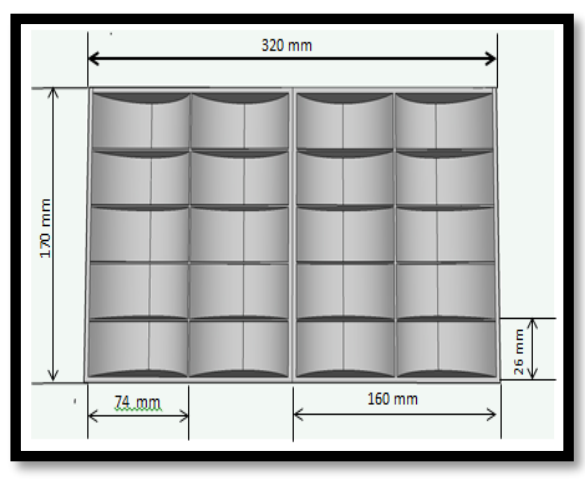

Gambar 3. Desain panci panggangan tampak atas

3. Dinding pembatas berfungsi untuk meminimalisir kecelakaan yang terjadi saat proses pemanggangan dange. 
Dinding pembatas ini terbuat dari plat, dan terdapat di setiap sisi luar tripleks pada bagian dalam dan bawah rangka. Dinding pembatas ini mempunyai ukuran yang sama dengan setiap sisi luar bagian atas rangka. Setiap diantara rangka dan dinding pembatas lalu ditutupi dengan dempul untuk menghindari adanya hawa panas yang keluar dari sisi samping dan bawah sehingga hawa panas hanya fokus ke arah panci panggangan dan wadah penampungan.

4. Pemasangan besi plat pada sekeliling alat pemanggang dange. Pada pemasangan besi plat di sekeliling dinding alat pemanggang dange ini dilakukan dengan menggunakan tang rivet dan paku clam sebagai alat bantu. Selanjutnya dilakukakan pengecatan pada rangka, dinding pembatas, dan dudukan menggunakan cat hijau muda.

\section{Prosedur Pengujian}

Prosedur pengujian alat hasil rancangan diuraikan sebagai berikut:

1. Menyiapkan alat dan bahan.

2. Menentukan objek pengujian, yaitu alat dapat melakukan proses pemanggangan.

3. Mengoperasikan alat pemanggang dange. Pengoperasian alat pemanggang ini dengan menghubungkan alat dengan listrik, kemudian menekan saklar sehingga alat dapat menjalankan proses pemanggangan.

4. Menghitung waktu yang digunakan pada proses pemanggangan tungku tradisional dan alat pemanggang dange listrik.

5. Menghitung biaya yang digunakan dalam proses pemanggangan tungku tradisional dan alat pemanggang dange listrik.

\section{Teknik Analisis Data}

Adapun teknik analisis data yang digunakan pada penelitian ini adalah teknik analisis data deskriptif kuantitatif, dimana hasil uji coba alat dimasukkan ke dalam tabel dan dideskripsikan berdasarkan hasil yang diperoleh dan membandingkan uji coba alat ini dengan tungku tradisional dan rice cooker.

Untuk mengukur efektifitas pemanggangan dange secara tradisional dan dengan menggunakan listrik disajikan dalam tabel. Kemudian, untuk menghitung uji efisiensi digunakan persamaan (Linda, 2013) sebagai berikut:

Efisiensi biaya $=\frac{\text { Harga dange }}{\text { Biaya yang digunakan }}$

Efisiensi biaya dari alat pemanggang dange listrik sebagai berikut:

Efisiensi biaya $=\frac{\text { Harga dange }}{\text { Biaya yang digunakan }}$

Keterangan:

Jika $>1$ efisien

Jika $<1$ tidak efisien

\section{Hasil dan Pembahasan}

\section{Hasil Perancangan Alat}

Hasil desain alat pemanggang dange ditampilkan pada Gambar 4 berikut ini.

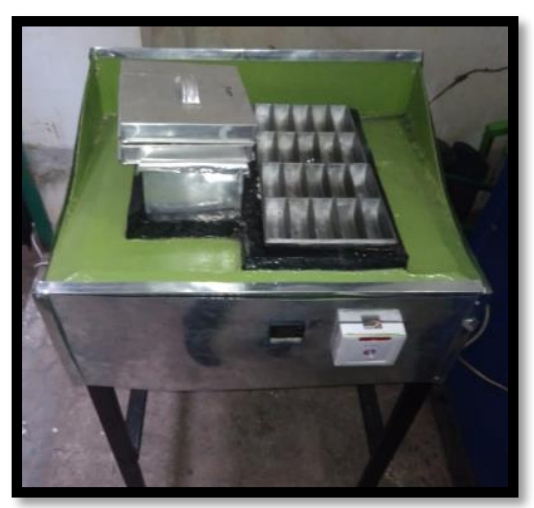

Gambar 4. Alat pemanggang dange 


\section{Hasil Uji Coba Alat}

1. Waktu pemanggangan

Berikut waktu pemanggangan dange secara konvensional dan menggunakan alat pemanggang dange.

a. Waktu memanggang menggunakan tungku tradisional (Tabel 1)

Pengamatan waktu pemanggangan menggunakan tungku tradisional dilakukan untuk mengetahui waktu yang digunakan oleh tungku tradisional sampai dange matang.

Tabel 1. Waktu pemanggangan tungku tradisional

\begin{tabular}{ccc}
\hline Ulangan & Waktu & $\begin{array}{c}\text { Jumlah } \\
\text { dange }\end{array}$ \\
\hline I & 14 menit 8 detik & 20 \\
II & 14 menit 22 detik & 20 \\
III & 15 menit 10 detik & 20 \\
\hline Rata-rata & 14 Menit 33 detik & 20 \\
\hline
\end{tabular}

b. Waktu Pemanggangan Menggunakan Alat Pemanggang Listrik

Pengamatan waktu pemanggangan menggunakan alat pemanggang listrik dilakukan untuk mengetahui waktu yang digunakan oleh alat pemanggang listrik sampai dange matang.

Tabel 2. Waktu pemanggangan alat pemanggang listrik

\begin{tabular}{ccc}
\hline Ulangan & Waktu & $\begin{array}{c}\text { Jumlah } \\
\text { Dange }\end{array}$ \\
\hline I & 13 menit 20 detik & 20 \\
II & 13 menit 20 detik & 20 \\
III & 13 menit 20 detik & 20 \\
\hline Rata-rata & 13 menit 20 detik & 20 \\
\hline
\end{tabular}

\section{Efisiensi biaya}

Berikut ini hasil perhitungan efisiensi biaya dengan menggunakan tungku tradisional dan rice cooker dibandingkan dengan menggunakan alat pemanggang dange listrik:

Diketahui: Biaya bahan 20 dange Rp. 20.000 Harga 20 dange Rp 25.000

a. Tungku tradisional dan rice cooker

$$
\text { Efisiensi biaya }=\frac{25.000}{20.000+397}=1,22 .
$$

b. Alat pemanggang dange listrik

$$
\text { Efisiensi biaya }=\frac{25.000}{20.000+135}=1,24 .
$$

Jadi, dapat disimpulkan penggunaan tungku tradisional dengan nilai efisiensi 1,22 dan alat pemanggang dange listrik yaitu 1,24 keduanya adalah efisien.

\section{Simpulan}

Peneletian ini menunjukan perbandingan efektifitas dan efisiensi antara tungku tradisional dengan alat pemanggang dange listrik. Pada uji efektifitas tungku tradisional rata-rata waktu adalah 14 menit 33 detik. Sedangkan pada penggunaan alat pemanggang dange listrik rata-rata waktu adalah 13 menit 20 detik. Biaya yang dibutuhkan pengrajin dange dalam sekali pemakaian menggunakan tungku tradisional dan rice cooker yaitu Rp 20.397. Biaya yang dibutuhkan menggunakan alat pemanggangan dange listrik yaitu $\mathrm{Rp}$ 20.135 . 


\section{Daftar Pustaka}

Arhamsyah M, Syam H, dan Jamaluddin P. 2018. Rancang Bangun Elemen Pemanas Listrik Dengan Memanfaatkan Udara Panas dari Elemen Pemanas Listrik. Jurnal Pendidikan Teknologi Pertanian. Vol 4: S196-S208 UNM, Makassar.

Asrianto, Jamaluddin P., dan Kadirman. 2018. Modifikasi Mesin Pengering Biji-Bijian dengan Bahan Bakar Tempurung Kelapa. Jurnal Pendidikan Teknologi Pertanian. Jurnal Pendidikan Teknologi Pertanian, Vol 4: S222-S231 UNM, Makassar.

Johan. 2016. Analisis Perpindahan Panas Radiasi Pada Inkubator Penetas Telur Ayam Berkapasitas 30 Butir. Universitas Muhammadiyah Jember.

Linda. 2013. Analisis efisiensi Obyek Wisata Di Kabupaten Wonosobo. Program Sarjana Fakultas Ekonomika dan Bisnis Universitas Diponegoro.

Mu'minin MA, Caronge MW, dan Kadirman. 2018. Modifikasi Tipe Dorong untuk Memaksimalkan Pembudidayaan Wortel (Daucus carrota). Jurnal Pendidikan Teknologi Pertanian. Vol 4: S21-S26 UNM, Makassar.

Suciati D. 2014. Rancang Bangun Prototipe dan Sistem Kendali Jarak Jauh Alat Pemanggang Berbasis Mikrokontroler Atmega 853. Palembang. Jurusan Teknik Komputer. Politeknik Negeri Sriwijaya. 